\title{
Increased cholesterylester transfer activity in complicated Type 1 (insulin-dependent) diabetes mellitus - its relationship with serum lipids
}

\author{
R.P.F. Dullaart ${ }^{1}$, J.E. M. Groener ${ }^{2}$, L.D. Dikkeschei ${ }^{1}$, D. W. Erkelens ${ }^{3}$ and H. Doorenbos ${ }^{1}$ \\ ${ }^{1}$ Departments of Endocrinology and Clinical Chemistry, University Hospital, Groningen, \\ 2 Department of Biochemistry I, Erasmus University, Rotterdam and \\ ${ }^{3}$ Department of Internal Medicine, University Hospital, Utrecht, The Netherlands
}

Summary. In Type 1 (insulin-dependent) diabetes mellitus, macrovascular complications and the increased risk for cardiovascular disease in patients with microvascular complications may be related to alterations in plasma cholesterylester transfer. The activity of cholesterylester transfer protein, which mediates cholesterylester transfer between lipoproteins and lipoprotein lipid levels, was assessed in 7 normolipidaemic control subjects, 7 Type 1 diabetic control subjects without complications, 11 Type 1 diabetic patients with microvascular complications (retinopathy, incipient nephropathy) and in 7 Type 1 diabetic patients with macrovascular atherosclerotic lesions.

The cholesterylester transfer activity was 30\% higher in the diabetic groups with macrovascular and microvascular lesions than in the 2 control groups. Very low + low density lipoprotein cholesterol was higher in the 3 diabetic groups than in the non-diabetic control group. High density lipoprotein cholesterol was not different. The cholesterylester transfer activity was correlated positively with $\mathrm{HbA1}$, urinary albumin excretion rate, serum cholesterol, very low + low density lipoprotein cholesterol and apolipoprotein B. The high density lipoprotein over very low +low density lipoprotein cholesterylester molar ratio was lower in the diabetic groups with micro- and macrovascular complications. A role for cholesterylester transfer activity in the lipoprotein abnormalities found in complicated Type 1 diabetes is suggested. A high cholesterylester transfer activity might be indicative of mechanisms which promote atherogenesis.

Key words: Type 1 (insulin-dependent) diabetes mellitus, cholesterol metabolism, cholesterylester transfer activity, microangiopathy, atherosclerosis.
The excess risk for cardiovascular disease in Type 1 (insulin-dependent) diabetes mellitus is observed predominantly in those patients who have developed diabetic nephropathy [1-3]. In association with atherosclerotic complications and with microvascular renal and retinal lesions increased levels of serum cholesterol, very low density lipoprotein (VLDL), low density lipoprotein (LDL) cholesterol and low levels of high density lipoprotein (HDL) cholesterol have been documented in Type 1 diabetes mellitus [4-8]. Among all other factors involved in lipoprotein metabolism, the process of cholesterylester transfer, mediated by the action of lipid transfer protein(s) will affect the distribution of cholesterylester between lipoproteins [9-12]. These lipid transfer protein(s) also catalyse the transfer and exchange of triacylglycerol and phospholipids [13-16].

In vitro the added activity of cholesterylester transfer protein (CETP) (denominated cholesterylester transfer activity (CETA)) and the composition and con- centration of the lipoproteins involved are important in the process of cholesterylester transfer [12, 17-20]. As yet, the (patho)physiologic relevance of this process for cholesterol transport has only been partially elucidated. It may provide a mechanism by which free cholesterol originating from either peripheral cells or other lipoproteins, after esterification by the action of lecithine cholesterol acyltransferase (LCAT), is transported from HDL to lipoproteins of lower density classes which can be catabolised at hepatic degradation sites [9, 21], but which are also capable of deposing cholesterol in vascular tissue $[10,22]$.

CETA, determined in an assay system in which the activity is measured independent of plasma lipoproteins, was higher in hypercholesteraemic and dysbetalipoproteinaemic subjects $[18,23]$. No data are available on CETA in Type 1 diabetes mellitus. The present study emphasises the role of CETA in Type 1 diabetic patients without and with micro- or macrovascular lesions. 
Table 1. Clinical characteristics of the 4 groups of subjects

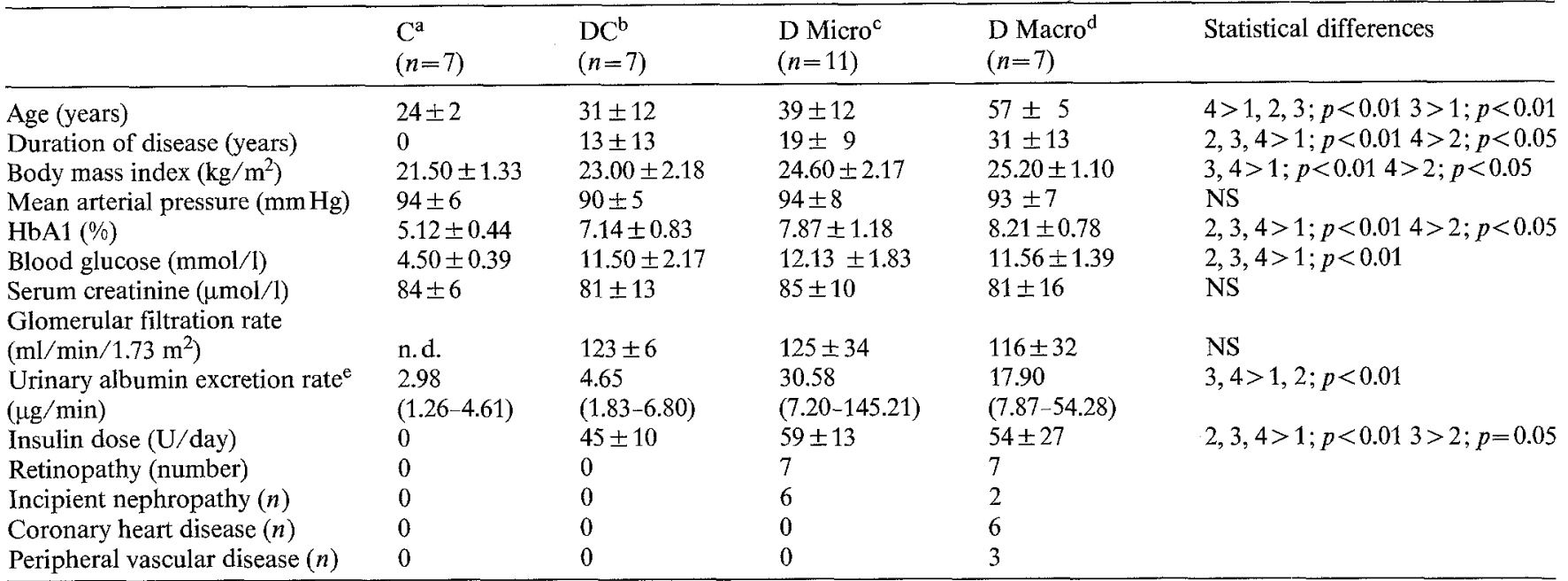

Results are given as mean \pm SD except $n$.d. denotes: not determined. ${ }^{a}$ Control subjects; ${ }^{b}$ Type 1 (insulin dependent) diabetic patients without complications; ${ }^{\mathrm{c}}$ Type 1 diabetic patients with microvascular lesions; ${ }^{\mathrm{d}}$ Type 1 diabetic patients with macrovascular lesions; ${ }^{\mathrm{e}}$ median (range)

\section{Subjects and methods}

\section{Subjects}

All subjects consented to the procedure after explanation of the purpose of the study. Four groups of subjects were investigated (Table 1): seven healthy control subjects (designated C), 7 Type 1 diabetic patients without complications (DC), 11 Type 1 diabetic patients with microvascular complications, either retinopathy, incipient nephropathy or both (D Micro) and 7 Type 1 diabetic patients with macrovascular complications, either coronary heart disease, peripheral vascular disease or both (D Macro).

Male subjects only participated in the study thus avoiding any effect of the menstrual cycle on lipid levels [24]. No subject had arterial hypertension (systolic blood pressure $>160 \mathrm{~mm} \mathrm{Hg}$, diastolic blood pressure $>90 \mathrm{~mm} \mathrm{Hg}$ ), diabetic nephropathy (defined as persistent proteinuria $>500 \mathrm{mg} / 24 \mathrm{~h}$ ) or overt hyperlipidaemia (defined as cholesterol $>8 \mathrm{mmol} / 1$ and/or triacylglycerol $>2.5 \mathrm{mmol} / \mathrm{l}$ ). All diabetic patients suffered from ketosis prone diabetes mellitus and were deemed insulin dependent on clinical grounds. The diabetic patients were recruited from the out-patient clinic and were in a stable metabolic condition by the use of multiple daily insulin injections. None of the subjects used other medication than insulin or oral anticoagulant drugs (D Macro). The last administration of insulin was $12 \mathrm{~h}$ and of anticoagulant drugs $24 \mathrm{~h}$ preceding the blood sampling.

Blood pressure was measured using a sphygmomanometer (Baumanometer, W.A. Baum Inc., New York, NY, USA). Korotkoff phase 5 was taken as the diastolic blood pressure. Mean arterial pressure (in $\mathrm{mm} \mathrm{Hg}$ ) was calculated as $0.67 \times$ diastolic pressure $+0.33 \times$ systolic pressure.

Retinopathy was assessed by fundoscopy through dilated pupils (range: background-proliferative). Incipient nephropathy was defined as a mean urinary albumin excretion of more than 30 and less than $200 \mu \mathrm{g} / \mathrm{min}$ in 3 consecutive overnight urine collection periods obtained just prior to the study. Urinary albumin excretion rates of this magnitude represent a risk factor associated with future development of diabetic nephropathy [25]. In D Macro coronary heart disease was documented by positive exercise testing, angiography or myocardial infarction (at least 6 months preceding the study). Peripheral vascular disease was assessed by positive exercise testing or angiography. Clinically relevant coronary heart disease and peripheral vascular disease were excluded by exercise testing in the 3 other groups. Serum creatinine was normal in all subjects. The glomerular filtration rate (GFR) was assessed in the diabetic patients with micro- or macrovas- cular lesions and in 2 diabetic control subjects using a previously described method [26]. The GFR was greater than $85 \mathrm{ml} / \mathrm{min} / 1.73 \mathrm{~m}^{2}$ in all tested subjects. No subject suffered from thyroid or liver disease as determined by routine thyroid and liver function tests.

As is shown in Table 1, the diabetic patients with macrovascular complications were older than the other subjects and had suffered from diabetes for a longer period of time than the diabetic patients without complications. These differences could be expected since atherosclerotic complications are related to age and duration of disease. The body mass index $\left(\mathrm{kg} / \mathrm{m}^{2}\right)$ was higher in D Macro. The metabolic control was adequate. The mean HbA1 was higher in D Macro than in DC. The dose of insulin was larger in D Micro than in DC. There were no differences in serum creatinine, GFR and mean arterial pressure between the groups.

\section{Laboratory methods}

Venous blood was drawn after a $12 \mathrm{~h}$ fast. Blood for lipid and CETA determinations was collected on ice and separated from erythrocytes immediately at $3000 \mathrm{rev} / \mathrm{min}$ for $15 \mathrm{~min}$. Samples were frozen at $-20^{\circ} \mathrm{C}$ and assayed within 4 weeks. The lipid and CETA assays were performed in duplicate in one run.

\section{Cholesterylester transfer activity assay}

CETA was assayed in serum using a previously described method [27]. By this method, CETA is determined after removal of endogenous VLDL and LDL by polyethylene glycoll precipitation and under conditions of LCAT inhibition. CETA was calculated as the bidirectional transfer of cholesterylester between $\left[1-{ }^{14} \mathrm{C}\right.$ oleate]-cholesterylester labelled LDL and HDL [28]. Data are expressed as nmol cholesterylester transfer $\cdot \mathrm{ml} \mathrm{serum}^{-1} \cdot \mathrm{h}^{-1}$. The within assay coefficient of variation was $2.7 \%$.

\section{Lipid assays}

Lipids were measured in serum and in the HDL containing supernatant fraction after precipitation. VLDL + LDL lipids were calculated as the difference between whole serum and the HDL fraction. The 
Table 2. Serum lipids and lipoproteins

\begin{tabular}{|c|c|c|c|c|c|}
\hline & $\begin{array}{l}\mathrm{C}^{\mathrm{a}} \\
(n=7)\end{array}$ & $\begin{array}{l}\mathrm{DC}^{\mathrm{a}} \\
(n=7)\end{array}$ & $\begin{array}{l}\text { D Micro }^{\mathrm{a}} \\
(n=11)\end{array}$ & $\begin{array}{l}\text { D Macro } \\
(n=7)\end{array}$ & $\begin{array}{l}\text { Statistical } \\
\text { differences }\end{array}$ \\
\hline Serum total cholesterol $(\mathrm{mmol} / \mathrm{l})$ & $4.53 \pm 0.61$ & $5.54 \pm 0.87$ & $5.54 \pm 0.97$ & $6.60 \pm 1.11$ & $\begin{array}{l}4>1 ; p<0.01 \\
2>1 ; p<0.05\end{array}$ \\
\hline HDL cholesterol $(\mathrm{mmol} / \mathrm{l})$ & $1.26 \pm 0.18$ & $1.22 \pm 0.19$ & $1.11 \pm 0.42$ & $1.20 \pm 0.27$ & NS \\
\hline VLDL + LDL cholesterol (mmol/l) & $3.28 \pm 0.59$ & $4.32 \pm 0.89$ & $4.43 \pm 0.98$ & $5.40 \pm 1.14$ & $\begin{array}{l}4>1 ; p<0.01 \\
2,3>1 ; p<0.05\end{array}$ \\
\hline
\end{tabular}

Results are given as mean $\pm \mathrm{SD} .{ }^{a}$ see legends to Table 1

HDL fraction was obtained by precipitation of VLDL + LDL with sodium phosphotungstate and $\mathrm{MgCl}_{2}$ for determination of cholesterol and triacylglycerol and by precipitation with polyethylene glycol6000 for determination of phospholipids [29, 30]. Total cholesterol was measured by gaschromatography [31], free cholesterol by a modification of this method in which the hydrolysis step was omitted. Cholesterylester was calculated as the difference between total and free cholesterol. Triacylglycerol was measured enzymatically on a SMACII autoanalyser (Technicon Instruments Inc., Tarrytown, NY, USA) [32]. Phospholipids were determined spectrophotometrically [33]. Apolipoprotein A1 and B were determined by immunoturbidimetry, using commercially available kits (Orion Diagnostica, Espoo, Finland).

\section{Other techniques}

Creatinine was measured on a SMAC-II autoanalyser. HbA1 was determined by colorimetry [34]. Glucose was measured on a Yellow Springs glucose analyser (YSI model 23A, Yellow Springs Inc., Yellow Springs, Ohio, USA).

\section{Statistical analysis}

Results are expressed as mean $\pm \mathrm{SD}$. Since urinary albumin excretion rates are positively skewed, these values are expressed as median and range. Comparison of data was performed using analysis of variance [35]. Least squares linear regression analysis was used for testing relationships between parametrically distributed data [36]. Log $\log _{10}$ transformed values of urinary albumin excretion rates were used. A p value of less than 0.05 was considered to be significant.

\section{Results}

The levels of serum lipids, apolipoprotein A1 and B are given in Table 2. Serum total cholesterol concentration was higher in D Macro and DC than in $C(p<0.01$ and $p<0.05$, respectively). Between the 3 diabetic groups there were no significant differences in total cholesterol levels. The VLDL + LDL cholesterol concentration was higher in the 3 diabetic groups than in C (D Macro vs $\mathrm{C}: p<0.01 ; \mathrm{D}$ Micro and DC vs C: $p<0.05$ ). Apolipoprotein $B$ was higher in D Macro than in the 3 other groups $(p<0.01)$. There were no significant differences between the 4 groups with respect to HDL cholesterol, serum triacylglycerol and apolipoprotein A1 concentrations.

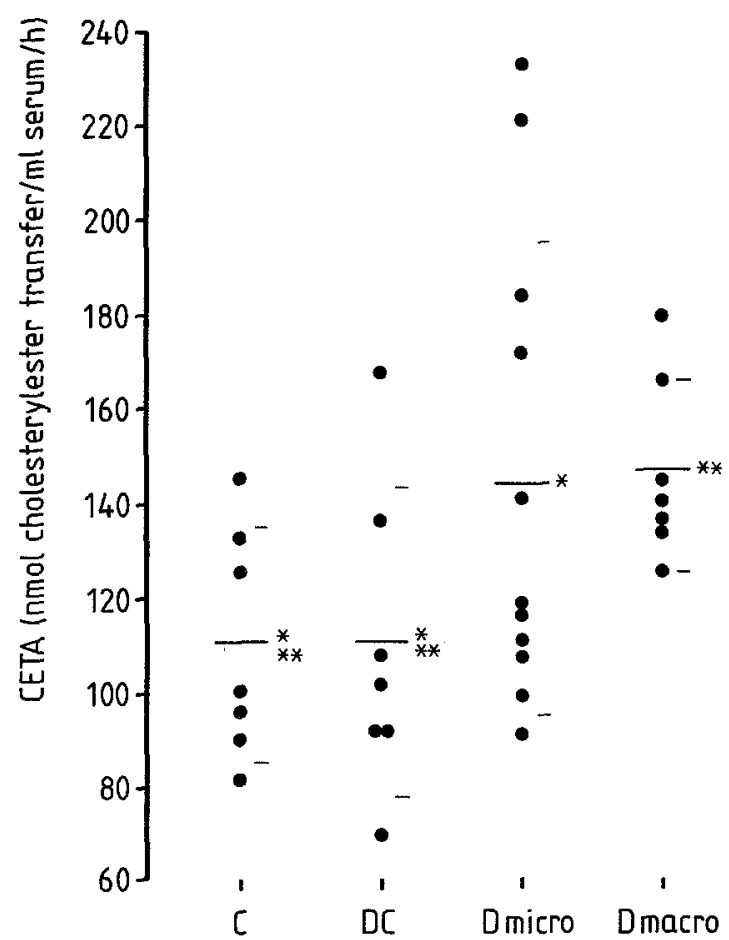

Fig. 1. Comparison of cholesterylester transfer activity (CETA) in 32 subjects. C: control subjects; DC: Type 1 (insulin-dependent) diabetic patients without complications; D Micro: Type 1 diabetic patients with microvascular lesions; D Macro: Type 1 diabetic patients with macrovascular lesions; *: D Micro $>\mathrm{C}$, DC: $p<0.05$; $* *$ : D Macro $>$ C, DC: $p<0.01$. Mean and SD values are indicated by bars

CETA was higher in D Macro and D Micro than in DC and C (D Macro vs DC and C: $p<0.01 ; D$ Micro vs DC and C: $p<0.05$ ) (Fig. 1). No differences in CETA were observed between C and DC or between D Micro and D Macro. Analysis of variance was also carried out among the data of the 3 diabetic groups only. The difference in CETA between DC, D Micro and D Macro remained present (D Micro and D Macro vs DC: $p \leq 0.05$ ). There was no significant correlation between CETA and age in the diabetic groups ( $r: 0.34:$ NS). In addition, CETA was determined in 11 other nondiabetic control subjects, aged $49 \pm 8$ years. In these subjects CETA was $108 \pm 34 \mathrm{nmol}$ cholesterylester transfer $\cdot \mathrm{ml}$ serum ${ }^{-1} \cdot \mathbf{h}^{-1}$, comparable to the values 
from $\mathrm{C}$ and $\mathrm{DC}$ and lower than the values from $\mathrm{D}$ Macro and D Micro.

The correlations of CETA and various other parameters are given in Table 3 . There was a significant correlation between CETA and HbA1, both in all subjects $(p<0.01)$ and in the diabetic subjects only $(p<0.05)$ and between CETA and urinary albumin excretion rates, both in all subjects $(p<0.01)$ and in the diabetic subjects only $(p<0.05)$. There was no significant relationship between CETA and blood glucose levels. Significant positive correlations of CETA and serum total cholesterol (all subjects: $p<0.01$; diabetic subjects only: $p=0.05$ ), VLDL + LDL cholesterol (all subjects: $p<0.01$; diabetic subjects only: $p<0.05$ ) and apolipoprotein B (all subjects: $p<0.05$; diabetic subjects only: $p=0.05$ ) were observed. CETA did not correlate significantly to HDL cholesterol, serum triacylglycerol and apolipoprotein $\mathrm{A} 1$.

The distribution of cholesterylester between HDL and VLDL+LDL was compared in the 4 groups of subjects. The HDL over VLDL+ LDL cholesterylester molar ratio was higher in $C$ and in $D C$ than in $D$ Macro $(p<0.01$ and $p<0.05$, respectively) and was higher in $\mathrm{C}$

Table 3. Relationships between cholesterylester transfer activity and various laboratory parameters

\begin{tabular}{|c|c|c|}
\hline & \multicolumn{2}{|c|}{ Correlation coefficients } \\
\hline & Diabetic subjects & All subjects \\
\hline $\mathrm{HbA1}$ & $0.44^{\mathrm{a}}$ & $0.45^{b}$ \\
\hline Blood glucose & 0.08 & 0.27 \\
\hline $\log _{10}$ urinary albumin excretion rate & $0.41^{\mathrm{a}}$ & $0.45^{\mathrm{b}}$ \\
\hline Serum cholesterol & $0.39^{\mathrm{a}}$ & $0.46^{\mathrm{b}}$ \\
\hline VLDL+ LDL cholesterol & $0.42^{\mathrm{a}}$ & $0.46^{\mathrm{b}}$ \\
\hline HDL cholesterol & -0.09 & -0.06 \\
\hline Serum triacylglycerol & 0.12 & 0.12 \\
\hline Apolipoprotein A1 & -0.25 & -0.07 \\
\hline Apolipoprotein B & $0.39^{\mathrm{a}}$ & $0.41^{\mathrm{a}}$ \\
\hline
\end{tabular}

Level of significance. ${ }^{\mathrm{a}} p \leq 0.05 ;{ }^{\mathrm{b}} p<0.01$ than in D Micro $(p<0.01)$. Between $\mathrm{C}$ and DC no significant difference was observed (Table 4 ). In the HDL fraction, no significant differences with respect to free cholesterol, cholesterylester, triacylglycerol and phospholipids, expressed as mol $\%$ of total lipids, were observed (Table 4). In the combined VLDL+LDL fraction, there were no differences in free cholesterol and phospholipids content nor in the free cholesterol/phospholipids molar ratio. The cholesterylester content in D Macro was higher than in $\mathrm{C}(p<0.05)$. The triacylglycerol content in D Macro was lower than in C $(p<0.05)$ (Table 4).

\section{Discussion}

The process of cholesterylester transfer mediated by CETP is supposed to be of major importance for the constellation of lipoproteins among the factors involved in lipoprotein metabolism [9-12, 37]. We report on an increased activity of CETP (CETA) in Type 1 diabetic patients in conjunction with micro- and macrovascular complications. The insulin-dependent state itself was not associated with alterations in CETA. It is very unlikely that the alterations in CETA could be attributed to differences in age among the groups of subjects studied, since there was no relation between CETA and age in the control subjects nor in the diabetic patients. The positive relations of CETA with serum total cholesterol, VLDL + LDL cholesterol, apolipoprotein $\mathrm{B}, \mathrm{HbA1}$ and urinary albumin excretion rate suggest an association of CETA with risk factors for the development of atherosclerosis, metabolic control and early renal lesions. In accordance, previous studies showed an effect of metabolic control and the presence of microvascular lesions on lipid levels $[3-8,38,39]$. These associations, however, do not provide evidence that in Type 1 diabetes, CETA itself is a cardiovascular risk factor. An increase in CETA has been reported in

Table 4. HDL and VLDL + LDL lipoprotein composition

\begin{tabular}{|c|c|c|c|c|c|}
\hline & $\begin{array}{l}\mathrm{C}^{\mathrm{e}} \\
(n=7)\end{array}$ & $\begin{array}{l}\mathrm{DC}^{\mathrm{e}} \\
(n=7)\end{array}$ & $\begin{array}{l}\text { D Micro }^{\mathbf{e}} \\
(n=10)\end{array}$ & $\begin{array}{l}\text { D Macro }^{\mathrm{e}} \\
(n=7)\end{array}$ & $\begin{array}{l}\text { Statistical } \\
\text { differences }\end{array}$ \\
\hline \multicolumn{6}{|l|}{ HDL } \\
\hline $\mathrm{FC}^{\mathrm{a}}(\mathrm{mol} \%)$ & $8.9 \pm 1.5$ & $8.4 \pm 2.1$ & $8.2 \pm 2.0$ & $7.6 \pm 2.0$ & NS \\
\hline $\mathrm{TG}^{\mathrm{c}}(\mathrm{mol} \%)$ & $3.6 \pm 0.8$ & $4.0 \pm 1.2$ & $4.8 \pm 1.5$ & $3.9 \pm 1.5$ & NS \\
\hline $\mathrm{PL}^{\mathrm{d}}(\mathrm{mol} \%)$ & $52 \pm 5$ & $52 \pm 5$ & $54 \pm 5$ & $53 \pm 6$ & NS \\
\hline $\mathrm{CE}^{\mathrm{b}}(\mathrm{mol} \%)$ & $44 \pm 6$ & $45 \pm 5$ & $46 \pm 4$ & $49 \pm 3$ & $4>1 ; p<0.05$ \\
\hline $\mathrm{TG}^{\mathrm{c}}(\mathrm{mol} \%)$ & $13 \pm 4$ & $11 \pm 7$ & $12 \pm 4$ & $9 \pm 5$ & $4<1 ; p<0.05$ \\
\hline $\mathrm{PL}^{\mathrm{d}}\left(\mathrm{mol}^{\circ} \%\right)$ & $23 \pm 5$ & $25 \pm 3$ & $24 \pm 3$ & $23 \pm 3$ & NS \\
\hline $\mathrm{FC} / \mathrm{PL}(\mathrm{mol} / \mathrm{mol})$ & $0.85 \pm 0.20$ & $0.82 \pm 0.18$ & $0.82 \pm 0.11$ & $0.84 \pm 0.18$ & NS \\
\hline $\begin{array}{l}\mathrm{HDLCE} /(\mathrm{VLDL}+\mathrm{LDL}) \\
\mathrm{CE}(\mathrm{mol} / \mathrm{mol})\end{array}$ & $0.46 \pm 0.15$ & $0.34 \pm 0.09$ & $0.31 \pm 0.17$ & $0.26 \pm 0.09$ & $\begin{array}{l}1>3,4 ; p<0.01 \\
2>4 \quad ; p<0.05\end{array}$ \\
\hline
\end{tabular}

Results are given as mean $\pm \mathrm{SD}$. $\mathrm{FC}^{\mathrm{a}}$ : denotes free cholesterol; $\mathrm{CE}^{\mathrm{b}}$ : denotes cholesterylester; $\mathrm{TG}^{\mathrm{c}}$ : denotes triacylglycerol; $\mathrm{PL}^{\mathrm{d}}$ : denotes phospholipids; ${ }^{\circ}$ see legend to Table 1. 
non-diabetic hyperlipidaemic and dysbetalipoproteinaemic subjects $[18,23]$. It should be noted that an increase in CETA could be the consequence of an increase CETP mass, but also of a decrease in possible inhibitor activity [40].

Little is known about the metabolic regulation of CETA. Diet studies showed that CETA increased after a single fat load in man and varied parallel with changes in VLDL and LDL cholesterol [18, 41-44]. In accordance with the proposed function of CETA to regulate cholesterylester distribution among lipoproteins [9-12, 21,23 , a decrease in the HDL over VLDL + LDL cholesterylester molar ratio was observed in complicated diabetic disease. The increase in cholesterylester and the decrease in triacylglycerol content in the combined VLDL + LDL fractions from patients with macrovascular complications should probably not be regarded as evidence for an effect of increase CETA on lipoproteins. Similar changes would be found with an increase in LDL mass per se, which suggested by the increase in apolipoprotein B in these patients.

A decrease of even reversal of cholesterylester net mass transfer from HDL to VLDL + LDL has been found in vitro in plasma from hypercholesterolaemic, dysbetalipoproteinaemic and Type 2 (non-insulin dependent) diabetic subjects $[45,46]$. An increase in net mass transfer of cholesterylester in dysbetalipoproteinaemic man has also been reported [18]. Net mass transfer of cholesterylester in vitro depends not only on CETA, but also on the concentration and composition of the lipoproteins involved [10-12, 17, 45]. In several conditions associated with an increased cardiovascular risk, an increase of free cholesterol and of the free cholesterol over phopholipids ratio, both in VLDL and LDL, was related to a decrease in cholesterylester net mass transfer into these lipoproteins [11, 45-47]. No alterations in these lipoprotein surface characteristics could be demonstrated in the combined VLDL + LDL fractions in the present study.

Apart from the process of cholesterylester transfer, many other important metabolic pathways such as hepatic cholesterol, triacylglycerol and apolipoprotein B production, lipoprotein and hepatic lipases and (non) receptor mediated lipoprotein uptake will affect the composition of lipoproteins [39]. We suggest that an increase in CETA may be involved in lipoprotein abnormalities found in complicated Type 1 diabetes. High CETA might be an early indication of an increased cardiovascular risk in this disease.

\section{References}

1. Borch-Johnsen K, Andersen PK, Deckert T (1985) The effect of proteinuria on relative mortality in Type 1 (insulin-dependent) diabetes mellitus. Diabetologia 28: 590-596

2. Borch-Johnsen K, Kreiner S (1987) Proteinuria: value as predictor of cardiovascular mortality in insulin-dependent diabetes mellitus. Br Med J 294: 1651-1654
3. Jensen T, Borch-Johnsen K, Kofoed-Enevoldsen A, Deckert (1987) Coronary heart disease in young Type 1 (insulin-dependent) diabetic patients with and without diabetic nephropathy; incidence and risk factors. Diabetologia 30: 144-148

4. Vannini P, Ciavarella A, Flammini M, Bargossi AN, Forlani G, Borgnino LC, Orsoni G (1984) Lipid abnormalities in insulin-dependent diabetic patients with albuminuria. Diabetes Care 7: $151-154$

5. Laakso M, Pyorala K, Sarlund H, Voutilainen E (1986) Lipid and lipoprotein abnormalities associated with coronary heart disease in patients with insulin-dependent diabetes mellitus. Arteriosclerosis $6: 679-684$

6. Jensen T, Stender S, Deckert T (1988) Abnormalities in plasma concentrations of lipoproteins and fibrinogen in Type 1 (insulindependent) diabetic patients with increased urinary albumin excretion. Diabetologia 31: 142-145

7. Winocour $\mathrm{PN}$, Durrington $\mathrm{PN}$, Ishola $\mathrm{M}$, Anderson $\mathrm{DC}$, Cohen $H$ (1987) Influence of proteinuria on vascular disease, blood pressure and lipoproteins in insulin-dependent diabetes mellitus. Br Med J 294: 1648-1651

8. Dornan TL, Carter RD, Bron AJ, Turner RC, Mann JJ (1982) Low density lipoprotein cholesterol: an association with the severity of diabetic retinopathy. Diabetologia 22: 167-170

9. Marcel YL (1982) Lecithin: cholesterol acyltransferase and intravascular cholesterol transport. Adv Lip Res 19:117-119

10. Tall AR (1986) Plasma lipid transfer proteins. J Lipid Res 27 : 361-367

11. Fielding CJ (1986) Inhibition and activation of cholesterylester transfer and its significance in plasma cholesterol metabolism. Adv Exp Med Biol 201: 205-210

12. Barter PJ, Hopkins GJ, Calvert GD (1982) Transfers and exchanges of esterified cholesterol between plasma lipoproteins. Biochem J 208: 1-7

13. Pattnaik NM, Mortes A, Hughes LB, Zilversmit DB (1978) Cholesterylester exchanges protein in human plasma, isolation and characterization. Biochim Biophys Acta 530: 428-438

14. Chajek T, Fielding CJ (1978) Isolation and characterization of lipid transfer protein(s) from human lipoprotein deficient plasma. Proc Natl Acad Sci USA 75: 3445-3449

15. Morton RE, Zilversmit DB (1982) Purification and characterization of lipid transfer protein(s) from human lipoprotein deficient plasma. J Lipid Res 23: 1058-1067

16. Tall AR, Abreu E, Shuman J (1983) Separation of a plasma phospholipid transfer protein from cholesterylester phospholipid exchange protein. $J$ Biol Chem 258: 2174-2178

17. Morton RE, Zilversmit DB (1983) Interrelationship of lipids transferred by the lipid transfer protein isolated from human lipoprotein deficient plasma. J Biol Chem 258: 11751-11757

18. Tall A, Granot E, Brocia R, Tabas I, Hesler C, Williams K, Denke M (1987) Accelerated transfer of cholesterylesters in dyslipidemic plasma. Role of cholesterylester transfer protein. J Clin Invest 79: 1217-1225

19. Eisenberg S (1985) Preferential enrichment of large sized very low density lipoprotein populations with transferred cholesterylesters. J Lipid Res 26: 487-494

20. Dullaart RPF, Groener JEM, Erkelens DW (1987) Effect of the composition of very low and low density lipoproteins on the rate of cholesterylester transfer from high density lipoproteins in man, studied in vitro. Eur J Clin Invest 17: 241-248

21. Fielding CJ, Fielding PE (1982) Cholesterol transport between cells and body fluids. Med Clin North Am 66:363-375

22. Zilversmit DB (1979) Atherogenesis: a postprandial phenomenon. Circulation 60: 473-485

23. Groener JEM, Van Rozen AJ, Erkelens DW (1984) Cholesterylester transfer activity. Localization and role in distribution of cholesterylester among lipoproteins in man. Atherosclerosis 50: 261-271

24. Jones DY, Judd JT, Taylor PR, Campbell WS, Nair PP (1988) Menstrual cycle effect on plasma lipids. Metabolism 37:1-2

25. Viberti GC, Jarrett RJ, Mahmud U, Hill RD, Argyropoulos A, Keen H (1982) Microalbuminuria as a predictor of clinical 
nephropathy in insulin-dependent diabetes mellitus. Lancet I: $1430-1432$

26. Donker AJM, van der Hem GK, Sluiter WJ, Beekhuis H (1977) A radioisotope method for simultaneous determination of the glomerular filtration rate and the effective renal plasma flow. Neth J Med 20: 97-103

27. Groener JEM, Pelton RW, Kostner GM (1986) Improved estimation of cholesterylester transfer exchange activity in serum or plasma. Clin Chem 32: 283-286

28. Barter PJ, Jones ME (1979) Rate of exchange of esterified cholesterol between human plasma low and high density lipoproteins. Atherosclerosis 34: 67-74

29. Lopes-Virella MF, Stone P, Ellis S, Colwell JA (1977) Cholesterol determinations in high density lipoproteins separated by three different methods. Clin Chem 23: 882-884

30. Demacker PNM, Hijmans AOM, Vos-Janssen HE, van't Laar A, Jansen AP (1980) A study of the use of polyethylene glycol in estimating cholesterol in high density lipoprotein. Clin Chem 26: 1775-1779

31. Hindriks FR, Wolthers BG, Groen A (1974) The determination of total cholesterol by gas-liquid chromatography compared with two other methods. Clin Chim Acta 77:207-215

32. Bucolo G, David H (1973) Quantitative determination of serum triglycerides by use of enzymes. Clin Chem 19:475-482

33. Zilversmit DB (1958) Phosphatides in plasma. In: Seligson D (ed) Standard methods of clinical chemistry. Academic Press, New York, pp 132-136

34. Fluckiger R, Winterhalter KH (1976) In vitro synthesis of hemoglobin A1C. FEBS Lett 71: 356-360

35. Duncan DB (1955) Multiple range and multiple F-tests. Biometrics $11: 1-42$

36. Diem K (1980) Wissenschaftliche Tabellen, 8th edn. Ciba Geigy Basel

37. Eisenberg S (1984) High density lipoprotein metabolism. J Lipid Res 25: 1017-1058

38. Glasgow AM, August GP, Hung W (1981) Relationship between control and serum lipids in juvenile-onset diabetes. Diabetes Care 4: $76-80$
39. Howard BV (1987) Lipoprotein metabolism in diabetes mellitus. J Lipid Res 28: 613-628

40. Son YSC, Zilversmit DB (1984) Purification and characterization of human plasma proteins that inhibit lipid transfer activities. Biochim Biophys Acta 795: 473-480

41. Groener JEM, Jacobs DMLHA, van Rozen AJ, Erkelens DW (1985) Diet, lipoproteins and cholesterylester transfer activity in hyperlipidemic subjects. Clin Nutr 4: 35-38

42. Tall A, Sammett D, Granot E (1986) Mechanisms of enhanced cholesterylester transfer from high density lipoproteins to apolipoprotein B-containing lipoproteins during alimentary lipemia. J Clin Invest 77: 1163-1172.

43. Son YSC, Zilversmit DB (1986) Increased lipid transfer activities in hyperlipidaemic rabbit plasma. Arteriosclerosis 6: 345-351

44. Quig DW, Zilversmit DB (1988) Plasma lipid transfer activity in rabbits: effects of dietary hyperlipidemias. Atherosclerosis 70: 263-271

45. Fielding PE, Fielding CJ, Havel RJ (1983) Cholesterol net transport, esterification and transfer in human hyperlipidemic plasma. J Clin Invest 71: 449-460

46. Fielding CJ, Reaven GM, Liu G, Fielding PE (1984) Increased free cholesterol in plasma low and very low density lipoproteins in non-insulin dependent diabetes mellitus: its role in the inhibition of cholesterylester transfer. Proc Natl Acad Sci USA 81: 2512-2516

47. Fielding CJ (1987) Factors affecting the rate of catalyzed transfer of cholesterylesters in plasma. Am Heart J 113: 532-537

Received: 30 June 1988

and in revised form: 1 December 1988

Dr. R.P.F. Dullaart

Department of Endocrinology

University Hospital

Oostersingel 59

NL-9713 EZ Groningen

The Netherlands 